University of South Florida

DIGITAL COMMONS

Digital Commons @ University of

@ UNIVERSITY OF SOUTH FLORIDA

South Florida

QMaSC: A Handbook for Directors of

Quantitative and Mathematics Support Centers

USF Libraries

$1-1-2016$

\title{
04. Addressing Diversity
}

Ibrahim Rosic

Mohawk Valley Community College

Follow this and additional works at: https://digitalcommons.usf.edu/qmasc_handbook

\section{Recommended Citation}

Ibrahim Rosic (2016), "Addressing Diversity", http://dx.doi.org/10.5038/ 9780977674435.ch4 in G.

Coulombe, M. O'Neill, M. Schuckers (Eds.) A Handbook for Directors of Quantitative and Mathematical

Support Centers, Neck Quill Press, http://scholarcommons.usf.edu/qmasc_handbook.

This Center Leadership and Management is brought to you for free and open access by the USF Libraries at Digital Commons @ University of South Florida. It has been accepted for inclusion in QMaSC: A Handbook for Directors of Quantitative and Mathematics Support Centers by an authorized administrator of Digital Commons @ University of South Florida. For more information, please contact digitalcommons@usf.edu. 


\section{Addressing Diversity}

(c) Ibrahim Rosic,

Mohawk Valley Community College

प्र

\section{Introduction}

As American society is increasingly becoming more diverse, postsecondary education institutions are making every effort to admit students with a variety of ages, experiences, talents, viewpoints, and cultural and educational backgrounds. Research shows that bringing diversity to higher education enhances personal growth opportunities for the students. For this reason, many colleges and universities strive to build and keep a diverse student population.

The majority of these diverse student populations enter the college campuses underprepared and unaware of expectations for college mathematics or quantitative coursework. As a result, student persistence and completion rates in higher education are low, particularly among underprepared students, returning adult students, culturally diverse students, and students with disabilities. These students are usually at risk of leaving college before they complete their education [1].

Quantitative and Math Support Centers (QMaSCs) play a significant role in helping these different groups of students achieve their academic goals. By staffing centers with diverse and welltrained tutors, providing a relaxed and attentive environment, collaborating with faculty members and other student support offices on the campus, and effectively promoting tutoring services, the success of centers working with a diverse student population could significantly improve.

Suggested Citation: Ibrahim Rosic (2016), "Addressing Diversity", http://dx.doi.org/10.5038/ 9780977674435.ch4 in G. Coulombe, M. O'Neill, M. Schuckers (Eds.) A Handbook for Directors of Quantitative and Mathematical Support Centers, Neck Quill Press, http://scholarcommons.usf.edu/qmasc_handbook.

This material is based upon work supported, in part, by the National Science Foundation under Grant DUE1255945. Any opinions, findings, and conclusions or recommendations expressed in this material are those of the author(s) and do not necessarily reflect the views of the National Science Foundation 


\section{Traditional Underprepared Students}

A traditional, underprepared college student could be defined as a high school graduate entering postsecondary education who is required to complete remedial or developmental work before taking college-level courses. The majority of underprepared students enter college lacking the background and motivation to succeed in, specifically, college-level math courses. The lack of basic academic skills puts these students at higher risk of leaving college before receiving their degrees [1]. "The success or failure of these students is directly related to the effectiveness and availability of tutorial service" [2].

Meeting the needs of underprepared students is one of the main challenges facing QMaSCs. "These students usually do not seek out assistance on their own and getting them to the academic support centers is a great accomplishment" 2]. Thus, center directors need to impose proactive efforts to reach out to these students and encourage them to utilize available support. First, the director should have tutors, other administrative staff members, themselves, or some combination of the three visit quantitative and mathematic courses and present the tutoring services to students. Awareness of possible additional support in learning mathematics helps create a sense of safety for underprepared students. Second, the director needs to establish a working relationship with faculty members teaching First-Year Experience Seminars, or some program for first-semester students, and encourage them to inform new students about math tutoring available on the campus. Third, tutor availability should be mentioned in the college catalogue and other college information brochures, the college website, student newsletters, and orientation sessions for new students. The QMaSC director could also use social networking sites, such as Facebook and Twitter, to further promote academic support among traditional students. Lastly, the director of the QMaSC should maintain a close relationship with other campus services such as counseling, advising, and housing to promote academic support through these offices.

At Mohawk Valley Community College (MVCC), the First-Year Experience Seminar (College Seminar) class is designed to connect new students with academic-support professionals and other resources available on the campus. During the first and second week of each semester, instructors of First-Year seminars bring their students to the Learning Center for a tour. By coming to the Learning Center, students have a chance to meet with tutors and become acclimated to the center for the future. In addition, students taking the class must complete an assignment that requires interaction with academic support professionals outside the classroom. After implementing these efforts in college seminar classes, the number of underprepared students utilizing Math Lab services had significantly increased.

Once the underprepared students actually come to the support centers, they usually have difficulty focusing on the problem at hand, and may not understand the role of the tutor [2]. To eliminate any confusion or insecurities, at the beginning of the first session, tutors should spend 
some time to get to know their students, their background, and how they feel about math. In addition, the student should sign a tutoring contract that clearly indicates the role of a tutor, and student expectations. During a tutoring session, students should feel comfortable asking questions, and expressing their frustration without being criticized. Tutoring must be focused on guiding and empowering the students, not completing problems for them. When working with the underprepared student, the tutor should pay attention to the student's study skills, note taking skills, and how much work is done by the student [2]. If necessary, the tutor should spend some time helping the student to acquire these basic academic skills.

Research shows that peer tutoring could be very effective for underprepared traditional college students. "The best answer to the question of what is the most effective method of teaching is that it depends on the goal, the student, the content and the teachers ... but the next best answer is students teaching other students" [3]. Research also shows that traditional college students are more comfortable learning with their peers, such that, "students can ask peers questions and not worry about 'looking stupid' or having their lack of understanding impact their grade" [4]. As a result, the director should staff the QMaSC with qualified peer tutors. Tutors should be selected based on their quantitative background and empathetic ability, and represent student diversity on the campus whenever possible. Peer tutors are students and may lack basic tutoring skills. Hence, it is essential to train peer tutors to work with underprepared students. The training should include topics such as establishing a comfortable tutoring environment, tutoring techniques, assisting students with math anxiety, assisting students with English as a Second Language, and understanding policies and procedures.

In an effort to adequately assist underprepared students, centers should provide walk-in tutoring and appointment-based tutoring. In walk-in tutoring programs, tutors will assist individual students over a short period of time, offer feedback, and answer specific questions. Tutors may work with multiple students simultaneously or in small groups. Students do not need to schedule an appointment for walk-in tutoring. As many students seek assistance shortly before their assignments are due, walk-in tutoring provides flexibility. In a survey conducted at the MVCC Math Lab, $78 \%$ of traditional students stated that they prefer walk-in tutoring over appointment-based tutoring [5]. In appointment-based tutoring programs, a tutor and a student work in a one-on-one setting. Appointment sessions are usually 30 minutes long and are arranged for the student and tutor at a mutually convenient time. In connection with the type of tutoring session, another important factor influencing the success of the support center with underprepared students is tutor availability [2]. A center's hours of operation should be comparable to students' schedules, meeting the needs of the students.

A majority of students who lack math study skills tend to memorize formulas and steps in solving problems, instead of understanding the process involved. In addition, many of these students suffer from math anxiety which leads to frustrations and a loss of interest. To address these issues, 
QMaSCs should offer workshops to help students learn how to study math, defeat anxiety, and set them on the right track for success. Finally, the center should provide useful handouts and the links to websites for additional support.

\section{Returning Adult Students}

Many higher education institutions define adult learners as college students over the age of 25 . These students are often referred to as nontraditional students. Reasons why adults may enter college include job loss, denied promotions due to the lack of a college degree, discharge from the military, divorce, or just wanting a better job.

A large number of adult students enter college unaware of the expectations and are underprepared for college-level course work. Generally, these students lack basic math skills, and get anxious at the thought of taking required math classes. In addition to being underprepared for college course work, adult learners often have extremely busy schedules due to job obligations, family responsibilities, health issues, and other outside factors that reduce the time available for education. Since these students face many challenges and obstacles, they may need additional support to achieve academic success in mathematics. Effective tutoring services may help adult students succeed in pursuing their degrees.

In an effort to adequately assist adult learners, directors have to be aware of the fact that adult students are significantly different from students coming directly from high-school. According to Nunn, adults learn best when the content and learning process is personally relevant to their life experiences or present concerns [6]. Malcolm Knowles identified four common characteristics of adult learners: (a) adult learners are self-directed and take responsibility for their own learning, (b) adult learners have an extensive life experience, (c) adult learners want to learn and they are internally motivated, and (d) adult learners need to know the reason for learning something [7]. The following shows how Knowles' Adult Learning Principles could be applied to tutoring for the adult student:

1. Adult learners are self-directed and take responsibility for their own learning [7]. The tutor should guide the student through a process of solving a problem and ask leading questions that would help the student understand each step. According to Fidishun, "adult learners resist learning when they feel others are imposing information, ideas or actions on them" [8]. Tutors should also allow the student to have control of the tutoring process, encourage independent learning and help the student gain confidence in his/her own ability. During the tutoring session, adult learners should be actively involved in the learning process for learning to be meaningful [9].

2. Adult learners use life experience as a foundation for their learning [7]. Adult learners may have had numerous life experiences upon reentering college, compared to the 
typical first-year student, and consequently, learn in different ways. These students want to apply their life experiences to learn new material [7]. In order to successfully tutor returning adult students, it is essential to know their learning styles. Thus, the director should encourage these students to take a learning style inventory test to help them identify their learning strategies preferences, strengths, and weaknesses. Once the learning style is identified, tutors should use the appropriate tutoring techniques that work best for the student [9]. Furthermore, tutors should find out about the student's interests and past experiences and try to relate problems at hand to the students past skills whenever possible.

3. Adult learners want to learn and they are internally motivated [7]. Adult students are in college because they want to learn, not because their parents made them attend, which may be the case for some traditional students. Unlike traditional underprepared students, adults will seek assistance to achieve their academic goals. When they struggle with material, they will go to a support center if the environment in the center suits their learning preferences. In order to effectively assist adults, the QMaSC has to provide a relaxed and motivated environment; the staff must be supportive, respectful and good listeners. Due to age differences, adult learners experience some difficulties connecting to younger students [10]. As a result, adult students would prefer to receive assistance from tutors closer to their age, so being conscientious as a staff to have the older mentors working with these students would provide a more comfortable working experience. Additionally, most of the adult students work and may not be able to come for tutoring during the day, so hours of operation should include evening and weekend hours.

When working with adults, it is essential to provide a comfortable, supportive environment that encourages learning. As with traditional, underprepared students, the tutor should start a session with a friendly greeting and a casual conversation to set the stage for a relaxed and attentive atmosphere. During a tutoring session, the tutor should establish rapport with the student, ask open-ended questions, and encourage the student to participate in the session as much as possible.

Knowles also argues that adult students are motivated to learn and stay in college by some external factors, such as promotions, a salary increase, and obtaining a better job. However, internal motivators such as improving self-esteem and desire to grow intellectually have greater impact on adult learners [8]. Having this in mind, the tutor should learn the student's possible motivations, and try to relate the material to the motivating factors.

4. Adult learners need to know the reason for learning something [7]. Most students desire to know why they are learning certain material and how will retaining the material personally benefit him or her; adult students are no different. "[Adult students] are less interested in learning for learning's sake than in learning to achieve some immediate or not 
too far distant life goals" [6]. They can be impatient with long discussions on theory, and like to see theory applied to practical problems. Therefore, whenever possible, the tutor should relate theory to real world applications.

\section{English as a Second Language (ESL) Students}

In most colleges, the English as a Second Language (ESL) student population includes a diverse profile of immigrants, refugees, and international students. ESL students face numerous challenges and obstacles in higher education. Besides the language barriers, the ESL student may have difficulty adapting to the demands of different cultures [11]. Furthermore, many ESL students may not have the background to understand textbooks that are written for students who are educated in the U.S. Consequently, these students may need additional support to achieve their academic dreams.

Despite the fact that mathematics is a universal language, many ESL students may struggle with math and science courses. They may know a mathematical concept, but it is the language and cultural background within math problems that they may not understand. This student population may need individualized attention provided by a tutor. In an effort to adequately assist ESL students, QMaSCs should offer a wide range of tutoring services, staff the centers with diverse tutors, provide an extensive tutor training on cultural differences, and constantly collaborate with ESL teaching faculty members and offices for international students.

Centers should provide a wide variety of academic support to meet the needs of the ESL student population. From my own experience as a math tutor, math instructor, and a former ESL student, I have learned that tutoring in a one-on-one setting is most effective and provides the best results in assisting ESL students. This is especially true for those enrolled in developmental

math courses. Furthermore, ESL students may benefit when tutored in a small group consisting of a diverse student population. In order to better assist ESL students, staff should also provide various handouts written in simple English covering different math or quantitative topics, and a description of commonly used formulas and terminology.

Another important factor influencing the success of a center with ESL students is tutor diversity. The QMaSC should be staffed with tutors who have different cultural backgrounds whenever possible. ESL students feel more comfortable when they walk into a center with students who also speak their language or relate to them on a personal level. In addition, it is a good idea to assist ESL students in their primary language whenever possible. Some math terms, word problems, and abstract ideas might not make sense until directly translated into the student's native language [12. Having a tutor who can explain the concept in the student's primary language will make tutoring more productive. 
At the beginning of each semester, the director should provide extensive training on how to tutor ESL students. Before the training, directors should find out the number of ESL students on the campus and the language they speak. The directors also should learn basic information about linguistic, cultural, and academic backgrounds of these students and share the information with tutors. For example, tutors should be aware that in some cultures female students may not want to shake hands with a male, or in some cultures it may not be acceptable for a student to ask for additional help. Furthermore, the math center director could include ESL faculty members into the training process to provide additional information and useful tips for assisting ESL students.

When it comes to actual tutoring, the center staff should be aware of the fact that quantitative material could be more challenging for some ESL students. Besides the conceptual understanding of mathematics, ESL students often have problems with math linguistics. As with adult students, it is essential to create a comfortable atmosphere during a tutoring session. The first tutoring session should take place in a one-on-one setting. Tutors should speak slowly, write down formulas, draw diagrams or pictures if appropriate, and paraphrase questions whenever the tutor sees confusion on the student's face. When asking a question, the tutor should wait for the student to respond. Increasing wait time will give students a chance to process what they have heard and formulate answers. ESL students could flourish in their quantitative classes with adequate academic support.

\section{$5 \quad$ Students with Disabilities}

An individual with a disability is a person with a physical or mental impairment which substantially limits one or more major life activities, such as walking, seeing, hearing, speaking, working, or learning [13. According to Federal Law, Section 504, “... colleges and universities may not discriminate in the recruitment, admission, educational process, or treatment of students" [13]. Due to this, the number of individuals with a wide range of disabilities in higher education has significantly increased.

Students with disabilities face a wide range of academic and personal challenges while on the college campuses. Faculty and support staff are legally obligated to provide necessary accommodations for these students to help them overcome many obstacles to achieve their academic goals [14]. Students with disabilities are often less academically prepared, and have lower self-confidence and self-esteem than students without disabilities [14]. As a result, these students may need extra support to thrive academically. The college support center plays an essential role in providing the necessary tools for these students to succeed.

In order to effectively accommodate students with disabilities, all tutoring locations must be wheelchair accessible, and tables should be accommodating for a wheelchair. In addition, tutoring centers should be staffed with well-trained tutors who could combine content knowledge with empathy. Lastly, the QMaSC director should regularly collaborate with the office of services for 
students with disabilities to become informed about each disabled student that seeks assistance within the center.

As mentioned above, students could be physically or mentally disabled. One of the major mental impairments is a learning disability. A learning disability is a neurological condition that interferes with a person's ability to receive, process, store and respond to information [15]. Learning disabilities can affect one's ability to read, write, speak, spell, compute math, reason, and also affect a person's attention, memory, coordination, social skills and emotional maturity [14]. Typical learning difficulties include dyslexia (problems with reading), dyscalculia (problems with math concepts), and dysgraphia (writing problems) [16]. In order to successfully assist a student with a learning disability, the tutor should be aware of the particular learning disabilities the student has. Since a student with a disability has a right to confidentiality, tutors may not be able to see the actual reports about the student's disability. Instead, the math center director could contact the office of services for students with disability to obtain the information about a particular student's strengths and weakness and possible strategies for assisting them. Once strengths and weaknesses for the disabled student are understood, tutors should use techniques and strategies that work best for the students.

When working with a college student with a learning disability, it is essential to find a location where the student feels comfortable to work on problems without fear of being embarrassed. Students with learning disabilities need to feel comfortable sharing their frustrations with the tutor. Based on my experience, students with learning disabilities learn best when they are tutored in a one-on-one setting by professional tutors. The majority of these students have a hard time disclosing their educational obstacles to their peers. Tutors should be extra careful when assisting a student with dyscalculia. These students have difficulty performing simple algebra and solving word problems. "Dyscalculia makes it impossible for learners to function with story problems that present math facts in sentences or paragraphs" [17]. When a tutor suspects that the student may have dyscalculia, the tutor should be extremely patient, repeat and paraphrase the question whenever there is confusion on the student's face, draw diagrams and charts, and encourage the student to use a calculator to perform any calculations when needed. Well-trained tutors who are able to combine content knowledge with empathy could help these students successfully complete their math requirements.

\section{Student Veterans}

With the end of the wars in Iraq and Afghanistan, many colleges and universities are seeing a significant increase of student veterans. Entering a college environment after serving in the military may be a difficult transition for the majority of veterans. Typically, student veterans tend to be older and are considered non-traditional students. Like other non-traditional students, veterans face 
many challenges and obstacles. A significant number of veterans have physical and/or psychological injuries. "A study conducted by the Veterans Administration reveals that nearly $30 \%$ of its patients who served in Iraq and Afghanistan have PTSD Post Traumatic Stress Disorder]" [18]. As a result of their injuries, veteran students have different needs than traditional college students and may need unique support to achieve their academic goals.

Research shows that veterans were less likely to seek academic support and getting them come to a QMaSC is quite a challenge [19]. For these reasons, the QMaSC director needs to use proactive efforts to reach out to these students and encourage them to utilize available support. The director should establish a close working relationship with the Veterans Office on campus (if one exists), or in town and ask their staff to make veterans aware of additional support. If possible, the director should invite a representative from the Veterans Office to participate in the tutor training and to inform tutors about veterans' obstacles and challenges. Furthermore, research found that academic success and persistence of student veterans depends on veterans' connection with students and faculty with military experience [19]. In an effort to attract student veterans to use the QMASC's services, the director should staff the center with tutors and support staff that have some military experience whenever possible. By working closely with the Veterans Office and hiring tutors with military experience, the director of a QMaSC could improve tutoring effectiveness and increase the number of veterans in the QMaSC.

\section{$7 \quad$ Creating Welcoming Atmosphere in QMaSCs}

In an effort to attract and motivate different types of students to utilize the services provided by the QMaSC, the director should staff the center with diverse and well-trained tutors and make sure that the atmosphere in the center is relaxed and non-threatening.

Studies show that qualified tutors constitute a successful QMaSC. Hiring qualified tutors is one of the main challenges facing the QMaSCs administrators, and whenever possible, tutors in the QMaSC should represent the cultural diversity that exists on campus. Close working relationships between the director and other offices (international students, ESL, students with disabilities, veterans office, student affairs, etc.) can be helpful in recruitment of potential tutors.

The effectiveness of QMaSCs with a diverse student population is strongly influenced by the tutor training. Directors could train their tutors in many different formats to ensure the quality of tutoring services. At Mohawk Valley Community College, two-day tutor training classes are offered at the beginning of each semester to help maintain the quality of tutoring services. The main goal of the tutor training is to ensure tutors understand the learning process in relation to content knowledge and to review and clarify the policies and procedures. Tutors should be trained to create a relaxed atmosphere in the tutoring session and to encourage independent learning. The director should invite the representative from the Office for Students with Disabilities to provide 
guidelines for tutoring students with disabilities. It would also be beneficial to include staff from the Office for International Students and ESL faculty members to address cultural differences during the tutor training. In addition, the director could ask faculty members teaching quantitative and math intensive classes to share their experience with tutors. By doing this, tutors will have a chance to meet the faculty and be aware of what faculty expect from tutors. Each semester, the director should observe and evaluate tutors and make appropriate suggestions for improvement.

QMaSCs should be conveniently located, and include adequate space and furnishings. The facilities should include: tutorial rooms, private offices and reception. All facilities must be wheelchair accessible and in compliance with relevant building codes. The physical appearance of each location in the center plays a significant role in getting students into the center. An attractive décor, such as seasonal and holiday decoration, posters of scientists from different countries, and student artwork, will enhance learning environment. For example, having a poster that says Albert Einstein had a learning disability may attract students with learning disabilities to utilize the tutoring service more often. Tutorial rooms need to be comfortable and quiet. Basic furnishing in tutorial rooms should include study carrels, tables, and chairs. In addition, every QMaSC should have several private offices for academic advising and individual tutoring for students that may not be comfortable sharing their frustration in larger groups. Also, the center should have a receptionist station to help students with scheduling and navigating the center. The reception area should also be decorated to promote diversity. By implementing the above recommendations, the director of a QMaSC could significantly improve the center success with diverse learners.

\section{Conclusion}

Today's higher education institutions are characterized by a diverse student population. College students differ in ability, academic preparation, age, ethnicity, language and cultural background. A significant number of these students enroll in college underprepared for rigorous college course work. One of the major obstacles in their educational adventure is mathematics. A large number of students do not learn math from lectures even when taught by excellent instructors. In order to successfully complete math requirements, many students will seek additional support. QMaSCs play a significant role in helping college students achieve academic success in quantitative and math-intensive science courses. The success of the QMaSCs with diverse student populations may be positively influenced by several factors. First of all, tutors should be selected based on their academic achievements and empathetic abilities, and represent the student diversity on the campus. Second, all tutors must be trained in tutoring techniques, learning styles, interpersonal skills, and self-esteem development. The learning environment in the center should be relaxed and non-threatening, so that students feel comfortable asking questions and expressing their frustration. Tutor availability must be comparable with students' schedules. Finally, the staff must publicize 
tutoring services and collaborate with faculty and other student support services on the campus. By executing the previous steps, the center director could significantly improve academic support for ever-increasing diverse student populations.

\section{Bibliography}

[1] N. Heckart, "Equal access: Universal design of tutoring and learning centers." DOIT, University of Washington, 2012. Accessed from http://www.washington.edu/doit/ equal-access-universal-design-tutoring-and-learning-centers June 2016.

[2] H. Baril, "Addressing diverse audience: Tutoring the underprepared student," in Tutor Training Handbook (S. Deese-Roberts, ed.), pp. 81-83, College Reading and Learning Association, 2003.

[3] W. J. McKeachie, Teaching and Learning in the College Classroom: A Review of the Research Literature. 1986.

[4] M. Hurley and M. Gilbert, "Basic supplemental instruction model," in Supplemental Instruction: Improving First Year Student Success in Higher Risk Courses, Monograph No.7 (M. E. Stone and G. Jacobs, eds.), (Columbia, SC), 2008. http://eric.ed.gov/?id=ED354839.

[5] "Mohawk Valley Community College Learning Center Survey," Spring 2013.

[6] D. Nunan, Learner-Centered English Language Education: The Selected Works of David Nunan. 2012.

[7] M. Knowles, Andragogy in Action: Applying Modern Principles of Adult Learning. 1984.

[8] Queensland Occupational Therapy Fieldwork Collaborative, "Adult learning theory and principles." Accessed from http://www.qotfc.edu.au/resource/?page=65375 on May 13, 2013.

[9] K. J. Rodrigues, "It does matter how we teach math," Journal of Adult Education, vol. 41, pp. 29-33, November 2012.

[10] S. L. Hagedorn, "Second chances: Older students in community colleges." Accessed from http://www.academia.edu/2650227/Second_Chances_Older_adults_in_community_ colleges on May 22, 2013.

[11] M. S. Sylvain, The Language of Success: A Case Study of the Academic Achievement of ESL Students Who Thrive in Spite of Language Barriers. PhD thesis, Capella University, 2013. Accessed from http://eric.ed.gov/?id=ED522266 on June 2016. 
[12] B. Jasper, J. Huber, S. Taube, F. Taylor, M. Klespis, M. Swarthout, C. Long, E. Avalos, L. Gerardo, and S. Boha, "Teachers guide to teaching mathematics for english language learners," November 2005. Accessed from http://txcc.sedl.org/events/previous/092806/ 8ExplorStrats/mell-teacher-guide.pdf on May 23, 2013.

[13] U. S. Department of Health and Human Services, Office for Civil Rights, "Your Rights Under Section 504 of the Rehabilitation." Accessed from http://www.hhs.gov/sites/default/ files/ocr/civilrights/resources/factsheets/504.pdf June 2016.

[14] Academic Skills Center University of Wisconsin , "Assisting students with disabilities." Accessed from http://www.uwec.edu/ASC/resources/studentswithdisabilities.htm.

[15] National Association of Special Education Teachers, "Introduction to learning disabilities." Accessed from http://www.naset.org/2522.0.html on May 29, 2013.

[16] Disabilities, Opportunities, Internetworking, and Technology Center at the University of Washington, "Learning disabilities." Accessed from http://www.washington.edu/doit/Faculty/ Strategies/Disability/LD/ on May 29, 2013.

[17] D. R. Jordan, Teaching Adults with Learning Disabilities. Malabar, Florida: Krieger Publishing Company, 1996.

[18] J. Reno, "Nearly $30 \%$ of Vets Treated by V.A. Have PTSD," 2013. Accessed from http://www.thedailybeast.com/articles/2012/10/21/ nearly-30-of-vets-treated-by-v-a-have-ptsd.html.

[19] D. DiRamio, "Transition 2.0: Using tintos model to understand student veteran persistence," ASHE Higher Education Report, vol. 37, no. 3, 2011.

[20] M. Snyder, "About MVCC." Mohawk Valley Community College website. Accessed from http: //www.mvcc.edu/about on June 3, 2013. 